\title{
ARAHAN PENGELOLAAN BLOK PEMANFAATAN \\ KESATUAN PENGELOLAAN HUTAN LINDUNG (KPHL) UNIT VI \\ PADA AREAL MODEL MIKRO DAS (MDM) TALAWAAN
}

\author{
Badrun Zaini \\ Bobby Vian Jhon Polii \\ Hengki Djemie Walangitan
}

\begin{tabular}{ll}
\hline Naskah diterima melalui Website Jurnal Ilmiah agrisosioekonomi@ unsrat.ac.id & : Kamis, 24 Oktober 2019 \\
Disetujui diterbitkan & : Jumat, 8 November 2019 \\
\hline
\end{tabular}

\begin{abstract}
This study aims to: (1) Analyze management models with Geographic Information Systems (GIS), (2) Arrange alternative directions for priority management with a combination of GIS and Analytical Hirarchy Process (AHP) and policy direction of land tenure in forest areas that are in the utilization block KPHL Unit VI which is in Talawaan MDM. The method used in this study is a survey method, namely: a method for obtaining field data by means of systematic observation, measurement and recording of the object under study and supported by the results of laboratory analysis. Sampling and field measurements are carried out using strata techniques with consideration to adjusting the location of the collection. Analysis of the data used: a) Estimating the amount of erosion using the formula Universal Soil Loss Equation (USLE), b) The combination of Geographic Information Systems and Analytical Hierarchy Process (AHP) is used to prepare alternatives for decision making. The results of this study indicated that the Management Model formed in the study area is the Community Forest Management Model (HKm) and Community Plantation Forest (HTR) and with a management period of 35 years and can be extended thereafter. Furthermore, the direction of management priorities according to AHP analysis with economic, ecological and social targets is to implement a management model with Land Utilities Type (LUT) Agrorestry, enrichment LUT and reforestation LUT with an economic target value of 429 points, ecological target value of 143 points and weight social target value of 429 points. The direction of the Government's policy for the completion of land tenure in this forest area is to provide management access to forest areas in the form of Social Forestry Program with the Community Forest Management Model (HKm) and Community Plantation Forest (HTR). ${ }^{*}$ prm*
\end{abstract}

Keywords: KPHL utilization, management priorities

ABSTRAK

Penelitian ini bertujuan untuk : (1) Menganalisis model pengelolaan dengan System Informasi Geografis (SIG), (2) Menyusun alternatif arahan prioritas pengelolaan dengan kombinasi SIG dan Analytical Hirarchy Process (AHP) serta arahan kebijakan penguasaan tanah pada kawasan hutan yang berada pada blok pemanfaatan KPHL Unit VI yang berada pada MDM Talawaan. Metode yang dipakai dalam penelitian ini adalah metode survei, yaitu : metode untuk memperoleh data lapangan dengan cara pengamatan, pengukuran, dan pencatatan secara sistematik terhadap objek yang diteliti dan didukung hasil analisis laboratorium. Pengambilan sampel dan pengukuran di lapangan dilakukan dengan teknik strata dengan pertimbangan mensesuaikan lokasi pengambilan. Analisis data yang digunakan : a) Pendugaan besaran erosi menggunakan rumus Universal Soil Loss Equation (USLE), b) Kombinasi Sistem Informasi Geografis dan Analytical Hierarchy Process (AHP) digunakan untuk menyiapkan alternatif-alternatif didalam pengambilan keputusan. Hasil penelitian ini menunjukkan bahwa Model Pengelolaan yang terbentuk pada wilayah penelitian berupa Model Pengelolaan Hutan Kemasyarakatan (HKm) dan Hutan Tanaman Rakyat (HTR) dan dengan jangka waktu pengelolaan selama 35 tahun dan dapat diperpanjang sesudahnya. Selanjutnya, arahan Prioritas pengelolaan sesuai analisa AHP dengan sasaran ekonomi, ekologi dan sosial adalah dengan melaksanakan model pengelolaan dengan Land Utilities Type (LUT) Agrorestry, LUT pengkayaan dan LUT reboisasi dengan bobot nilai sasaran ekonomi sebesar 429 poin, nilai sasaran ekologi 143 poin dan bobot nilai sasaran sosial sebesar 429 poin. Adapun Arahan kebijakan Pemerintah untuk penyelesaian penguasaan tanah dalam kawasan hutan ini adalah dengan memberikan akses pengelolaan terhadap kawasan hutan berupa Program Perhutanan Sosial dengan Model Pengelolaan Hutan Kemasyarakatan (HKm) dan Hutan Tanaman Rakyat (HTR). ${ }^{* e p r m *}$

Kata kunci : pemanfaatan KPHL, prioritas pengelolaan 


\section{PENDAHULUAN}

\section{Latar Belakang}

Penyelenggaraan Kehutanan sebagaimana Undang-Undang Nomor : 41 tahun 1999 tentang Kehutanan satu diantaranya adalah bertujuan untuk mengoptimalkan fungsi hutan yang meliputi : fungsi konservasi, fungsi lindung, dan fungsi produksi untuk mencapai manfaat ekologi, ekonomi dan sosial dengan prinsip keseimbangan dan lestari. Akan tetapi dalam perkembangannya hutan mendapat tekanan yang begitu kuat sehingga fungsi ekonomis hutan menjadi lebih dominan, sedangkan fungsi ekologis dan fungsi sosial hutan kurang mendapat perhatian sehingga banyak mengalami gangguan dan kerusakan sehingga, dibutuhkan suatu kelembagaan untuk memastikan agar pengelolaan secara ekonomi dan ekologi dapat berjalan dengan baik.

Pembangunan Kesatuan Pengelolaan Hutan (KPH) di Indonesia dipandang sebagai solusi strategis untuk melakukan kegiatan yang berorientasi pada perencanaan spasial dengan memperhatikan kondisi sosial ekonomi lokal serta menyatukan arah pelaksanaan kegiatan Pemerintah, Pemerintah Provinsi dan Pemerintah Kabupaten/ Kota (Kartodihardjo 1998, Kartodihardjo et al. 2011, Baplan 2006a). Rencana Strategis (Rentra) Kementerian Kehutanan tahun 2010-2014 yang berisikan delapan program Kementerian Kehutanan dan satu diantaranya program tersebut adalah pembentukan dan penetapan pembangunan 120 Unit KPH diseluruh Indinesia.

Unit-Unit KPH yang berada di Provinsi Sulawesi Utara telah ditetapkan dengan Keputusan Menteri Kehutanan Nomor: SK.796/Menhut-VII/2009 tanggal 7 Desember 2009 yang terdiri dari sembilan Unit KPH yang meliputi 4 unit KPHL dan 5 unit KPHP. Satu diantara KPHL yang telah siap beroperasi adalah KHPL Unit VI yang berada pada wilayah Kabupaten Minahasa Utara, Kota Bitung dan sebagian kecil diwilayah Kota Manado dengan wilayah pengelolaan seluas 27.100,52 ha.

Sesuai Peraturan Menteri Kehutanan Nomor P.6/Menhut-II/2009 tanggal 29 Januari 2009 tentang pembentukan wilayah Kesatuan Pengelolaan Hutan

(KPH) bahwa kriteria dan indikator dalam pembentukan wilayah KPH mempertimbangkan beberapa aspek diantaranya adalah : a.
Karakteristik biofisik lapangan; b. Kondisi sosial ekonomi masyarakat sekitar; c. Potensi sumberdaya alam dan d. Keberadaan hak-hak atau izin usaha pemanfaatan hutan dan penggunaan kawasan hutan. Kriteria dan indikator inilah yang kelak membentuk blok-blok tertentu pada wilayah $\mathrm{KPH}$.

Blok-blok pada KPH terdiri atas petakpetak yang dibentuk dengan metoda desk analiss berdasarkan satuan pemetaan lahan atau Land mapping Unit $(L M U)$ yang didesain dengan mengikuti batas alam maupun menggunakan pendekatan Micro Catchment Area atau areal model DAS mikro (MDM). Model DAS Mikro merupakan suatu wadah pengelolaan DAS dalam skala lapang yang digunakan sebagai tempat atau media untuk memperagakan proses pola partisipatif dalam pengelolaan kegiatan rehabilitasi hutan dan lahan, teknik-teknik konservasi tanah dan air, usaha tani yang sesuai dengan kemampuan lahan, sosial ekonomi dan kelembagaan masyarakat.

Salah satu model DAS yang berada di wilayah KPHL Unit VI adalah Model DAS Mikro (MDM) Talawaan dengan luas 3.579 ha yang merupakan daerah hulu sub DAS Talawaan. Sebagai areal Model DAS Mikro, permasalahan klasik yang dihadapi adalah terjadinya degradasi hutan, yakni perubahan dari areal hutan menjadi lahan pertanian. Perubahan tutupan lahan akan mempengaruhi pola tatanan spasial ekologi yang pada akhirnya menyebabkan terjadinya evolusi dalam fungsi ekosistem (Wang et al., 2006). Beberapa variabel karakteristik ekologi diantaranya produktivitas biologi (tanaman biomassa), unsur hara (bahan organik tanah dan kandungan nitrogen), dan kapasitas konservasi air (Turner et al., 2003; Hietel et al., 2004). Dampak dari penggunaan lahan dan perubahan tutupan lahan pada sumberdaya lingkungan DAS ditandai dengan adanya sedimentasi yang diakibatkan oleh erosi tanah (Vörösmarty et al., 2000).

Disisi lain degradasi hutan juga menyebabkan permasalahan land tenure. Tenure berasal dari bahasa latin "tenere" yang mencakup arti: memelihara, memegang, memiliki. Istilah land tenure dijelaskan dalam konteks legal sebagai sistem pemanfaatan dan/atau kepemilikan tanah. Istilah land tenure dapat juga menjelaskan bagaimana seseorang atau pihak tertentu memangku dan/atau memiliki tanah (Gamin, 2014). Penguasaan dan kepemilikan lahan dikawasan hutan selalu menjadi hot issue dalam setiap penyelesaian permasalahan lahan yang berada didalam kawasan hutan. 


\section{Tujuan Penelitian}

Tujuan dalam penelitian ini adalah :

1. Menganalisis model pengelolaan blok pemanfaatan KPHL Unit VI yang berada pada MDM Talawaan dengan Sistem Informasi Geografis (SIG).

2. Menyusun arahan prioritas pengelolaan dengan mengkombinasi SIG dan Analytical Hirarchy Process (AHP) serta arahan kebijakan terkait penguasaan tanah pada kawasan hutan yang berada pada blok pemanfaatan KPHL Unit VI yang berada pada Model Mikro Das (MDM) Talawaan.

\section{METODE PENELITIAN}

\section{Lokasi dan waktu Penelitian}

Lokasi penelitian adalah blok pemanfaatan KPHL Unit VI yang berada pada areal MDM Talawaan. Secara administratif lokasi penelitian berada diKecamatan Dimembe Kabupaten Minahasa Utara. Waktu penelitian dilakukan selama 3 (tiga) bulan, terhitung mulai bulan Maret 2018 sampai dengan Mei 2018. Adapun letak lokasi penelitian sebagaimana tertera pada Gambar 1.

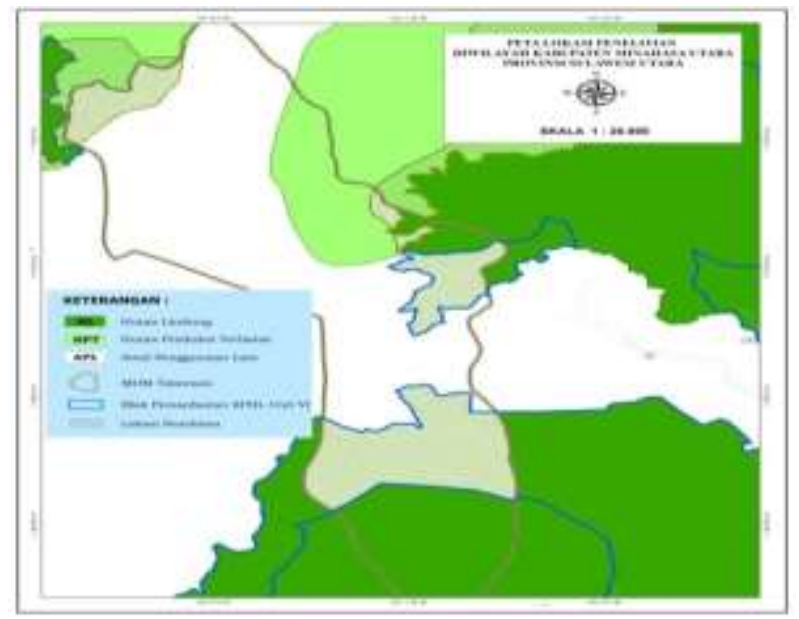

Gambar 1. Peta Lokasi Penelitian

\section{Alat dan Bahan}

a. Alat yang digunakan dalam penelitian diantaranya perangkat komputer dengan system operasi ArcGIS 10.1, software MS Office.

b. Data sosial ekonomi menggunakan data statistik Dimembe dalam angka tahun 2018.

c. Data curah hujan bulanan di wilayah studi dari BMKG Kayuwatu Sulawesi Utara. Data panjang lereng dan persentase kelerengan dianalisis dari peta topografi skala $1: 50.000$ serta data fisik tanah (tekstur dan bahan organik) untuk menghitung nilai erodibilitas menggunakan data sekunder hasil analisis fisik tanah yang tersebar di wilayah studi sesuai data JICA (2001) dalam Walangitan (2012) dan Walangitan, 2013).

\section{Metode}

Metode yang dipakai dalam penelitian ini adalah metode survei, yaitu : metode untuk memperoleh data lapangan dengan cara pengamatan, pengukuran, dan pencatatan secara sistematik terhadap objek yang diteliti dan didukung hasil analisis laboratorium. Pengambilan sampel dan pengukuran di lapangan dilakukan dengan teknik strata dengan pertimbangan mensesuaikan lokasi pengambilan. Tahapan pengumpulan data penelitian terdiri atas 3 tahap yaitu :

a. Penyiapan peta kerja yang bertujuan untuk memperoleh gambaran informasi awal kondisi biogeofisik lokasi penelitian.

$b$. Pengumpulan Data Primer, merupakan data yang diperoleh atau dikumpulkan secara langsung dari sumbernya. Metode yang digunakan untuk mengumpulkan data primer yaitu dengan metode survey, diantaranya dengan melakukan observasi dan wawancara termasuk terhadap Pihak yang memanfaatkan, menggunakan dan menguasai tanah didalam kawasan hutan yang berada pada wilayah penelitian.

c. Pengumpulan Data Sekunder, merupakan data tambahan berupa Peta dan dokumen penunjang yang berhubungan dengan KPHL Unit VI yaitu : Peta Kawasan Hutan dan Konservasi Perairan Provinsi Sulawesi Utara, data digital areal MDM Talawaan, peta kelas lereng, jenis tanah, termasuk didalamnya buku Tata Hutan dan Buku Rencana Pengelolaan Hutan Jangka Panjang (RPHJP) KPHL Unit VI serta dokumen penujang lainnya.

\section{Analisa Data}

Analisis data yang digunakan dalam penelitian ini yaitu pendugaan analisis besaran erosi dengan USLE dan Pembuatan Model Pengelolaan dengan kombinasi Sistem Informasi Geografis dan Analytical Hierarchy Process (AHP).

\section{a. Pendugaan besaran erosi}

Pendugaan besaran erosi menggunakan rumus Universal Soil Loss Equation (USLE), persamaan umum yang dikembangkan oleh Wischmeier \& Smith (1978) Rumus USLE yang digunakan :

$$
\text { A = R K L S C P }
$$

Dimana :

$\mathrm{A}=$ banyaknya tanah yang tererosi (ton/ha/th) 
$\mathrm{R}=$ faktor indeks (erosivitas) hujan

$\mathrm{K}=$ faktor erodibilitas tanah

$\mathrm{L}=$ faktor panjang lereng

$\mathrm{S}=$ faktor kecuraman lereng

$\mathrm{C}=$ faktor vegetasi penutup tanah dan pengelolaan

$\mathrm{P}=$ faktor tindakan khusus untuk konservasi tanah

Masing-masing variabel dalam persamaan USLE dihitung sebagai berikut :

1) Faktor erosivitas (R) hujan adalah kemampuan hujan dalam mengerosi tanah. Indeks erosivitas curah hujan (R) dihitung dengan menggunakan data curah hujan rata-rata bulanan tahun 2016 2018. Persamaan yang digunakan dalam menentukan tingkat erosivitas hujan dalam Aryad, 2010 menggunakan Metode Lenvain digunakan untuk menghitung nilai $\mathrm{R}$ sebagai berikut :

$\mathrm{R}_{\mathrm{m}}=2,21$ (Rain) $\mathrm{m}^{1,36}$

Dimana :

$\mathrm{R}_{\mathrm{m}} \quad=$ erosivitas curah hujan bulanan

(Rain) ${ }_{\mathrm{m}}=$ curah hujan bulanan dalam $\mathrm{cm}$

2) Faktor erodibilitas $(\mathrm{K})$ tanah merupakan faktor kepekaan tanah terhadap erosi. Indeks erodibilitas dihitung dengan menggunakan data hasil analisis fisik tanah JICA (2001) yang selanjutnya dihitung dengan menggunakan monograf $\mathrm{K}$.

3) Faktor panjang dan kemiringan lereng (LS). Menurut Laflen and Moldenhauer (2003) dalam As-syakur (2008), faktor panjang lereng yaitu perbandingan antara erosi dari tanah dengan suatu panjang lereng tertentu terhadap erosi dari tanah dengan panjang lereng $22 \mathrm{~m}$ di bawah keadaan yang identik. Sedangkan faktor kemiringan lereng, yaitu perbandingan antara besarnya erosi yang terjadi dari suatu tanah kecuraman lereng tertentu, terhadap besarnya erosi dari tanah dengan lereng $9 \%$ di bawah keadaan yang identik.

Tabel 2. Panjang Lereng Menurut Tipe Penggunaan (L)

\begin{tabular}{lc}
\hline Tipe penggunaan lahan & panjang lereng $(\mathrm{m})$ \\
\hline Sawah & 40 \\
Tegalan tanaman jagung & 1 \\
Tegalan tanaman sayuran & 1 \\
Perkebunan dengan tutupan lahan baik & 40.9 \\
Hutan sekunder & 58 \\
Hutan alam & 58 \\
Kebun campuran (tan. semusim + cengkeh) & 20,9 \\
Kebun campuran (tan. cengkih + pepohonan) & 20.9 \\
Pemukiman & 25.0 \\
\hline
\end{tabular}

Sumber: JICA, 2001 dalam Walangitan, 2012

Selanjutnya nilai panjang lereng menggunakan persamaan 3 (Dirjen RRL,1998)

$\mathrm{L}=\sqrt{\frac{L o}{22}}$
$\mathrm{L}=$ Nilai faktor panjang lereng

Lo $=$ Panjang lereng

Persen kemiringan lereng (S) dihitung pada peta topografi selanjutnya rata- rata nilai $S$ menggunakan tabel nilai faktor kemiringan lereng sebagaimana disajikan pada Tabel 3.

Tabel 3. Nilai Faktor Kemiringan Lereng (S)

\begin{tabular}{lcc}
\hline Kelas Lereng & Kemiringann & Rata-rata Nilai S \\
\hline II & $0-8$ & 0.4 \\
II & $8-15$ & 1.4 \\
III & $15-25$ & 3.1 \\
IVI & $25-40$ & 6.1 \\
V & $>40$ & 11,9 \\
\hline Sumber : Pedoman penyusunan RTL-RLKT, Dirjen RRL (1998)
\end{tabular}

Perhitungan LS dapat juga dilakukan dengan menggunakan Sistem Informasi Geografis. Mekanisme yang mengkombinasikan data raster Shuttle Radar Topography (SRTM) yang dirubah menjadi Digital Elevation Model (DEM). Perhitungan panjang LS sepenuhnya dilakukan secara digital.

4) Indeks Pengelolaan Tanaman (C), yang dianalisis melalui pengamatan lapangan suatu usahatani. Data yang diamati adalah jenis tanaman, pola tanam, masa bera, kondisi penutupan lahan dan pengelolaan bahan organik tanah. Nilai indeks C selain diperoleh dari hasil - hasil penelitian, juga menggunakan tabel nilai C (Arsyad 2010) dan JICA (2001).

5). Faktor Upaya Pengelolaan Konservasi (P) Indeks $\mathrm{P}$ diukur berdasarkan bentuk aplikasi konservasi tanah metode mekanis yaitu tipe terasering (bentuk dan dimensi) yang diamati di lapangan. Nilai indeks $\mathrm{P}$ diperoleh dengan membandingkan kondisi lapangan dengan nilai indeks $\mathrm{P}$ berdasarkan hasil-hasil penelitian yang tersedia sebagaimana pada pedoman penyusunan RTL-RLKT (Dirjen RRL, 1998), dan Arsyad (2010).

\section{b. Analytical Hierarchy Process (AHP)}

Analytical Hierarchy Process (AHP) digunakan untuk menyiapkan alternatif-alternatif didalam pengambilan keputusan. Prosedur dalam menggunakan metode AHP terdiri dari beberapa tahap yaitu (Jayanath dan Garmini, 2003) yaitu :

a) Menyusun hirarki dari permasalahan yang dihadapi Penyusunan hirarki yaitu dengan menentukan tujuan yang merupakan sasaran sistem secara keseluruhan pada level teratas. Level berikutnya terdiri dari kriteria-kriteria untuk menilai atau mempertimbangkan dan menentukan alternatif-alternatif tersebut. 
b) Menentukan prioritas elemen dengan langkah langkah sebagai berikut:

- Langkah pertama dalam menentukan prioritas elemen adalah membuat perbandingan secara berpasangan,yaitu membandingkan elemen secara berpasangan sesuai kriteria yang di berikan. Untuk perbandingan berpasangan digunakan bentuk matriks. Matriks bersifat sederhana, berkedudukan kuat yang menawarkan kerangka untuk memeriksa konsistensi, memperoleh informasi tambahan dengan membuat semua perbandingan yang mungkin dan menganalisis kepekaan prioritas secara keseluruhan untuk merubah pertimbangan.

Selanjutnya mengisi matrik perbandingan berpasangan yaitu dengan menggunakan bilangan untuk merepresentasikan kepentingan relatif dari satu elemen terhadap elemen lainnya yang dimaksud dalam bentuk skala dari 1 sampai dengan 9. Skala ini mendefinisikan dan menjelaskan nilai 1 sampai 9 untuk pertimbangan dalam perbandingan berpasangan elemen pada setiap level hirarki terhadap suatu kreteria di level yang lebih tinggi. Struktur hirarki dapat dilihat pada tabel 4 dan gambar 2 .

Tabel 4. Skala banding berpasangan pada Analytic

\begin{tabular}{|c|c|c|}
\hline $\begin{array}{c}\text { Intensitas } \\
\text { kepentingan }\end{array}$ & Keterangan & Penjelasan \\
\hline 1 & Kedua elemen sama & \multirow{3}{*}{$\begin{array}{l}\text { Dua elemen } \\
\text { menyumbangkan } \\
\text { sama besar pada sifat } \\
\text { pengalaman dan } \\
\text { pertimbangan sedikit } \\
\text { menyokong satu } \\
\text { elemen atas lainnya. } \\
\text { Pengalaman dan } \\
\text { pertimbangan dengan } \\
\text { kuat menyokong satu } \\
\text { elemen atas lainnya }\end{array}$} \\
\hline 3 & $\begin{array}{l}\text { Elemen yang satu lebih } \\
\text { penting dari elemen lainnya. }\end{array}$ & \\
\hline 5 & $\begin{array}{l}\text { Elemen yang satu } \\
\text { esensial/sangat penting } \\
\text { ketimbang elemen yang } \\
\text { lainnya. }\end{array}$ & \\
\hline & & \multirow{6}{*}{$\begin{array}{l}\text { Satu dengan kuat } \\
\text { disokong dan } \\
\text { dominannya telah } \\
\text { terlihat dalam } \\
\text { praktek } \\
\text { Bukti yang } \\
\text { menyokong satu } \\
\text { elemen yng satu atas } \\
\text { yang lain memiliki } \\
\text { ingkat penegasan } \\
\text { yang tinggi yang } \\
\text { mungkin } \\
\text { menguatkan } \\
\text { kompromi } \\
\text { diperlukan antara dua } \\
\text { pertimbangan }\end{array}$} \\
\hline 7 & $\begin{array}{l}\text { Satu elemen jelas lebih } \\
\text { penting dari elemen lainnya }\end{array}$ & \\
\hline & & \\
\hline 9 & $\begin{array}{l}\text { Satu elemen mutlak lebih } \\
\text { penting dari elemen lainnya }\end{array}$ & \\
\hline $2,4,6,8$ & $\begin{array}{l}\text { Nilai-nilai antara diantara } \\
\text { dua pertimbangan yang } \\
\text { berdekatan }\end{array}$ & \\
\hline Kebalikan & $\begin{array}{l}\text { Jika untuk aktivasi } 1 \\
\text { mendapat satu angka bila } \\
\text { dibandingkan dengan } \\
\text { aktivitas } j \text {. maka } j \\
\text { mempunyai nilai kebalikan } \\
\text { bila dibandingkan dengan } i\end{array}$ & \\
\hline
\end{tabular}

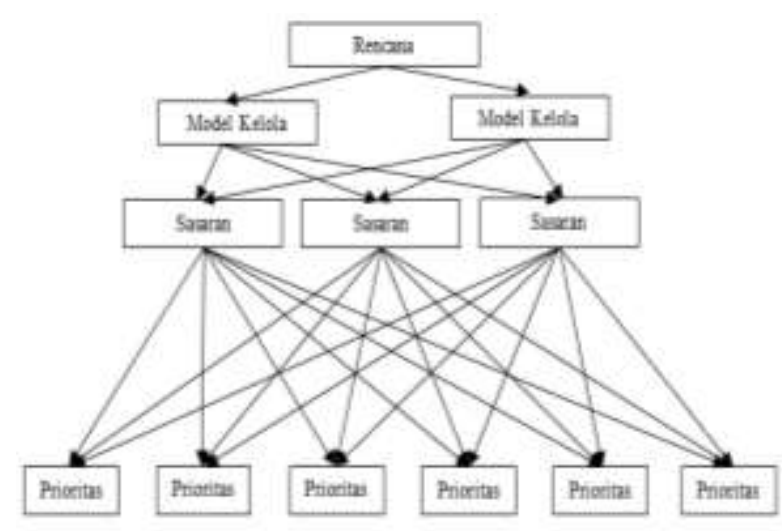

Ganaber 2. Hirankiki dai Anahinc Hierarchn Proses (AHP)

\section{DESKRIPSI UMUM LOKASI PENELITIAN}

Wilayah penelitian terletak pada koordinat geografis $124^{\circ} 58^{\prime} 52^{\prime \prime}-125^{\circ} 2^{\prime} 17^{\prime \prime}$ Bujur Timur (BT) dan $1^{\circ} 28^{\prime} 43^{\prime \prime}$ - $134^{\prime} 59^{\prime \prime}$ Lintang Utara (LU). Secara administrasi, wilayah Desa penelitian yaitu: Desa Klabat, Desa Pinilih dan Desa Wasian yang berada diKecamatan Dimembe Kabupaten Minahasa Utara Provinsi Sulawesi Utara. Wilayah penelitian merupakan areal blok pemanfaatan KPH Unit VI yang berada pada MDM Talawaan yang berada pada ketinggian 280 - 870 mdpl. Fungsi kawasan yang yang berada dilokasi penelitian diantaranya: Hutan Lindung (HL) Gn. Wiau, HL Gn. Klabat, Hutan Produksi Terbatas (HPT) Gn. Saoan, dan HPT Gn. Wiau dengan luas wilayah penelitian 798,47 $\mathrm{Ha}$.

\section{Penutupan lahan}

Penutupan Lahan (land cover) yang selanjutnya disingkat PL, yang didefinisikan sebagai penyebutan kenampakan biofisik di permukaan bumi yang terdiri dari areal vegetasi, lahan terbuka, lahan terbangun, tubuh air dan lahan basah (Lillesand et al. 1990). Penggunaan lahan adalah pengaturan, kegiatan dan input terhadap jenis tutupan lahan tertentu untuk menghasilkan sesuatu, mengubah atau mempertahankannya. Hasil penafsiran citra satelit resolusi sedang tahun 2018 (Anonim, 2019), kondisi tutupan lahan pada lokasi penelitian lebih dari $47 \%$ didominasi oleh pertanian lahan kering campur semak. Secara keseluruhan komposisi tutupan lahan pada wilayah penelitian adalah : Hutan sekunder 230,88 Ha (28,92\%), Pertanian Lahan Kering 189,45 Ha (23,73 \%), Pertanian Lahan Kering Campur Semak 378,16 Ha $(47,36 \%)$. Adapun Kodefikasi yang digunakan untuk analisis penutupan lahan yaitu : Hs digunakan untuk penutupan lahan Hutan Sekunder, Kode Pt digunakan untuk penutupan lahan Pertanian lahan kering dan Kode Pc, digunakan untuk penutupan lahan Pertanian lahan kering campur semak. 


\section{Kelas Kelerengan}

Analisis kelas kelerengan sebagaimana tersaji pada peta kelas kelerengan lokasi penelitian. Hasil analisis kelerengan didominasi oleh KL curam dengan sebesar 72,83 $\%$ dari seluruh luas wilayah penelitian. Secara keseluruhan kelas lereng wilayah penelitian terdiri dari : kelerangan datar (0-8\%) seluas 96,99 $\mathrm{Ha}$ atau $12,15 \%$, landai $(8-15 \%)$ seluas $3,25 \mathrm{Ha}$ atau $0,41 \%$, agak curam $(16-25 \%)$ 47,91 Ha $(6,00 \%)$ curam $(26-40 \%)$ seluas 581,53 Ha atau 72,83\% dan sangat curam $(>40 \%)$ seluas $68,82 \mathrm{Ha}$ atau $8,62 \%$. sebagaimana tersaji pada gambar 3 .

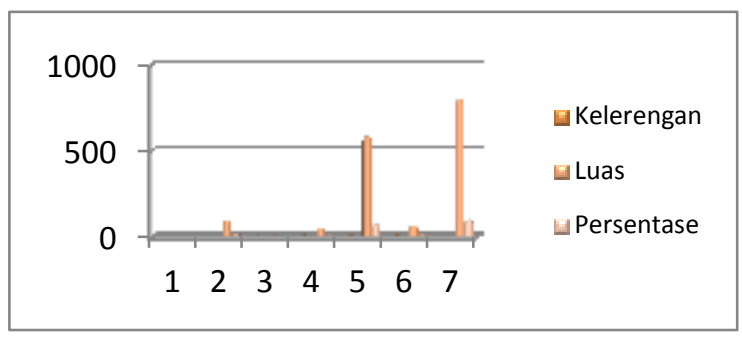

Gambar 3. Kelas Kelerengan pada pada wilayah penelitian

\section{Jenis Tanah}

Jenis tanah wilayah studi berdasarkan klasifikasi tanah USDA. Menurut Joseph (2010) dalam Walangitan dkk, (2013) jenis tanah di DAS Talawaan didominasi oleh ordo tanah Inceptisol, sebagian Alfisol, Entisol, dan Ultisol. Namun dalam kajian ini disajikan dalam asosiasi tanah, karena keterbatasan data. Tanah di uraikan berdasarkan Satuan Peta Tanah (SPT) sebaran jenis tanah dapat dilihat pada Tabel 5 .

Tabel 5. Jenis Tanah Wilayah penelitian

\begin{tabular}{|c|c|c|}
\hline No & TAKSONOMI & Luas \\
\hline 1 & Dystropepts Dystrandepts Tropudults & 131,22 \\
\hline 2 & Dystropepts Humitropepts Tropohumults & 291,33 \\
\hline 3 & Dystropepts Tropudulfts Humitropepts & 9,87 \\
\hline 4 & Humitropepts Dystrandepts Hydrandepts & 366,05 \\
\hline \multicolumn{2}{|r|}{ Jumlah } & 798,47 \\
\hline
\end{tabular}

\section{Kondisi Sosial Lokasi Penelitian}

Ketiga Desa penelitian berada di Kecamatan Dimembe. Jumlah Penduduk Kecamatan Dimembe Tahun 2017 berjumlah 25.476 jiwa. Cakupan luas wilayah $158,12 \mathrm{~km}$, dengan demikian kepadatan penduduknya mencapai $161 \mathrm{jiwa} / \mathrm{km}$. Jumlah penduduk Desa Klabat sebanyak 1.278 jiwa sedangkan Desa Tumataras memiliki jumlah penduduk sebanyak 1.634 jiwa. Rasio jenis kelamin dapat dilihat pada Tabel 10.
Tabel 6. Rasio Jenis Kelamin pada lokasi penelitian

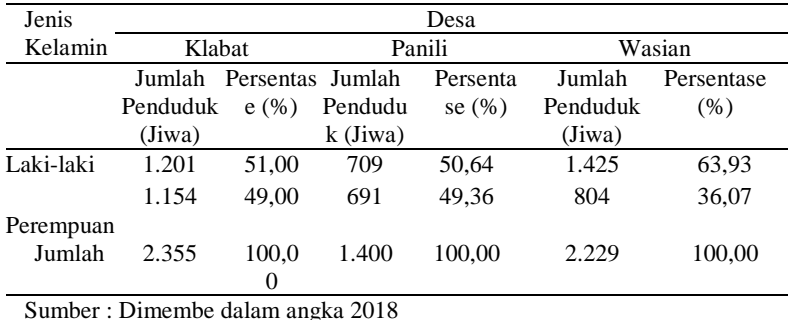

\section{Pekerjaan}

Pekerjaan masyarakat di 3 (tiga) desa ini sangat beragam, mulai dari petani, pegawai Negeri Sipil, Anggota TNI dan Polri dan sebagian merupakan karyawan swasta.

\section{Sarana Pendidikan}

Sarana pendidikan yang terdapat pada 3 (tiga) Desa Penelitian sebagaimana tertera pada Tabel 7.

Tabel. 7 Sarana Pendidikan pada lokasi Penelitian

\begin{tabular}{|c|c|c|c|c|c|}
\hline \multirow[b]{2}{*}{ Desa } & \multicolumn{4}{|c|}{ Sarana Pendidikan } & \multirow[t]{2}{*}{ Keterangan } \\
\hline & TK & SD & $\begin{array}{l}\text { SMP } \\
\end{array}$ & SMA & \\
\hline Klabat & 2 & 3 & 1 & - & \\
\hline Panili & 1 & 2 & - & - & \\
\hline Wasian & 3 & 2 & - & - & \\
\hline Jumlah & 1.278 & 100,00 & 1.634 & 100,00 & \\
\hline
\end{tabular}

\section{HASIL DAN PEMBAHASAN}

\section{Land Mapping Unit (LMU)}

Land Mapping Unit (LMU) adalah Satuan Unit Lahan terkecil yang mempunyai kesamaan kondisi biofisik terutama dalam hal tingkat kerusakan/kekritisan, fungsi kawasan, ketebalan tanah gambut dan morfologi Daerah Aliran Sungai (Anonim, 2014). LMU atau Satuan Unit Lahan dapat pula dibentuk dengan menggunakan komponen lainnya yang homogen dalam suatu hamparan. Dalam penelitian ini komponen yang digunakan dalam pembentukan satuan unit lahan adalah penutupan lahan, kelerengan, jenis tanah. Besaran nilai dari ketiga komponen ini sebagaimana tersaji pada Deskripsi Umum Lokasi Penelitian

Untuk mempermudah menganalisis data digunakan kodefikasi unttuk masing-masing komponen yang dianalisis. Kodefikasi yang digunakan untuk Penutupan lahan (PL) adalah Hutan Sekunder (Hs), pertanian lahan kering $(\mathrm{Pt})$, pertanian lahan kering campur semak (Pc). 
Kodefikasi yang digunakan untuk diskripsikan kelas lereng I, II, III, IV dan V. Kode I digunakan sebagai kodefikasi lerengan datar, kode II digunakan untuk kelas lereng landai, kode III digunakan untuk kelas lereng agak curam, kode IV digunakan untuk kelas lereng curam dan kode $\mathrm{V}$ digunakan untuk kelas lereng sangat curam. Adapun kodefikasi yang digunakan untuk jenis tanah yaitu $\mathrm{H}, \mathrm{Hy}$, Trm dan Trp. Kode $\mathrm{H}$ digunakan sebagai kodefikasi Dystropepts Tropudulfts Humitropepts, Hy digunakan sebagai kodefikasi Humitropepts, Trm digunakan sebagai kodefikasi Dystrandepts Hydrandepts dan Kode Trp digunakan sebagai kodefikasi pada jenis tanah Dystropepts Dystrandepts Tropudults.

Hasil analisis dengan menggunakan system informasi geografis didapatkan satuan lahan yang terbentuk adalah 26 satuan unit lahan sebagaimana tersaji pada Tabel 8.

Tabel 8. Land Mapping Unit Blok Pemanfaatan KPHL Unit VI pada MDM Talawaan

\begin{tabular}{|c|c|c|c|c|c|c|c|}
\hline No & Kod_LR & Kod_Tanah & Kod_PL & Kod_LMN & N_KwSn & No_LMU & Luas \\
\hline 1 & v & Trm & Pt & VTrmPt & HPT Gn. Sagan & 1 & 15,52 \\
\hline 2 & 1 & Trm & $\mathrm{Pt}$ & $\Pi \mathrm{rmpt}$ & HPT Gn, Saoan & 2 & 21,78 \\
\hline 3 & $\mathrm{v}$ & Trm & $P_{c}$ & VTrmPc & HPT Gn, Saoan & 3 & 13,08 \\
\hline 4 & 1 & Trm & $P_{C}$ & MrmPc & HPT Gn. Saoan & 4 & 6,45 \\
\hline 5 & IV & Trm & $P_{c}$ & IVTrmPc & HPT Gn. Saoan & 5 & 8.87 \\
\hline 6 & III & Trm & $P_{C}$ & $\| I T r m P c$ & HPT Gn. Saoan & 6 & 2,52 \\
\hline 7 & III & Trm & $\mathrm{Pt}$ & IllTrmpt & HPT Gn. Saoan & 7 & 39,50 \\
\hline 8 & III & $\operatorname{Trp}$ & $\mathrm{Pt}$ & IIITrpPt & HPT Gn. Saoan & 8 & 3,98 \\
\hline 9 & 1 & Irp & $\mathrm{Pt}$ & ITrpPt & HPT Gn. Saoan & 9 & 5,52 \\
\hline 10 & 1 & Trm & $\mathrm{Pt}$ & ITrmPt & HPT Gn. Saoan & 10 & 5,69 \\
\hline 11 & 1 & $H$ & $\mathrm{Pt}$ & IHPt & HPT Gn. Saoan & 11 & 7,93 \\
\hline 12 & III & $H$ & $\mathrm{Pt}$ & IIIHPt & HPT Gn. Saoan & 12 & 1,95 \\
\hline 13 & IV & Trm & $P_{C}$ & IVTrmPc & HPT Gn. Wiau & 13 & 18,66 \\
\hline 14 & IV & Trm & HS & NTTmHS & HLGn. Wiau & 14 & 23,17 \\
\hline 15 & IV & Trm & HS & NTImHS & HPT Gn. Wiau & 15 & 10,47 \\
\hline 16 & IV & Trm & $P C$ & IVTrmPC & HLGn. Wiau & 16 & 60,27 \\
\hline 17 & IV & Trm & HS & NImHS & HLGn. Wiau & 17 & 2,37 \\
\hline 18 & IV & Irm & $P t$ & IVImpt & HLGn. Wiau & 18 & 62,98 \\
\hline 19 & 1 & $\operatorname{Irp}$ & $P t$ & IrpPt & HL Gn. Klabat & 19 & 23,65 \\
\hline 20 & 1 & Trp & PC & ITrpPc & HLGn. Klabat & 20 & 25,94 \\
\hline 21 & IV & Trp & Pc & IVTrper & HLGn. Klabat & 21 & 72,13 \\
\hline 22 & II & Ho & Ps & HHyPc & HLGn. Klabat & 22 & 3,24 \\
\hline 23 & IV & Hir & Pc & IVHeype & HL Gn, Klabat & 23 & 167,29 \\
\hline 24 & IV & $\mathrm{Hr}$ & $1 \mathrm{HS}$ & IVHYHS & HLGn. Klabat & 24 & 151,66 \\
\hline 25 & v & Hir & 15 & VHYHS & HLGn, Klabat & 25 & 40,21 \\
\hline 26 & IV & Hir & 15 & IVHyHS & HL Gn, Klabat & 26 & 3,65 \\
\hline \multicolumn{7}{|c|}{ Jumlah } & 798,47 \\
\hline
\end{tabular}

Wilayah penelitian berada pada 4 kawasan hutan yaitu : Kawasan Hutan Lindung (HL) Gn. Klabat, Kawasan HL Gn. Wiau, Kawasan Hutan Produksi Terbatas (HPT) Gn. Wiau dan Kawasan HPT Saoan. Sesuai dengan tabel 8 diatas $L M U$ yang terbentuk pada masing-masing kawasan hutan pada wilayah penelitian sebagaimana tersaji pada gambar 4,5,6 dan gambar 7 .

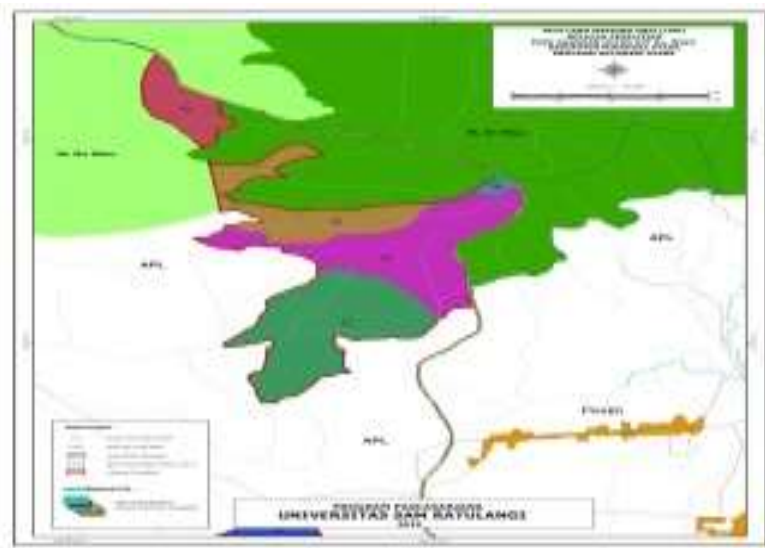

Gambar 4. Peta Land Mapping pada kawasan HPT Gn. Wiau

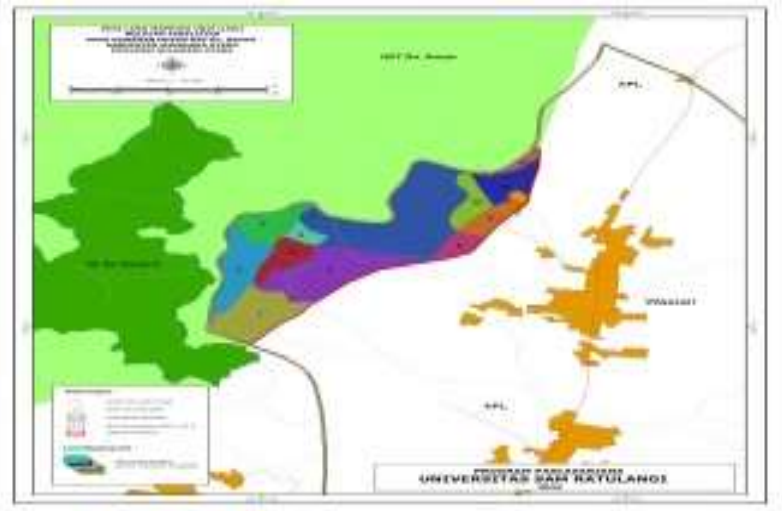

Gambar 5. Peta Land Mapping pada kawasan HPT Gn. Saoan

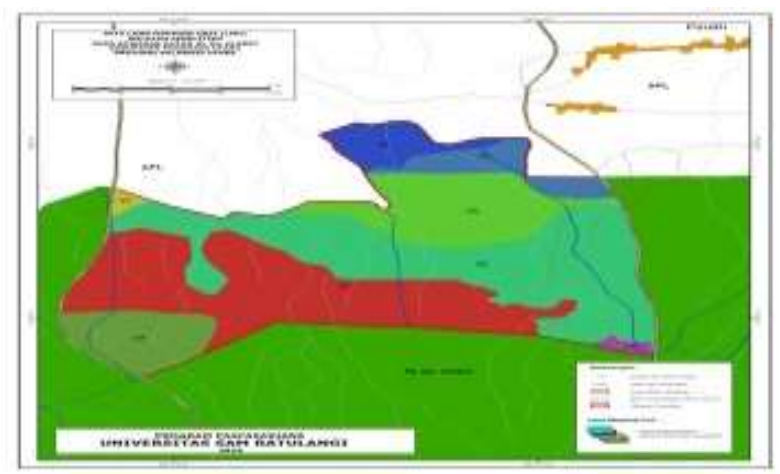

Gambar 6. Peta Land Mapping pada kawasan HL Gn. Klabat

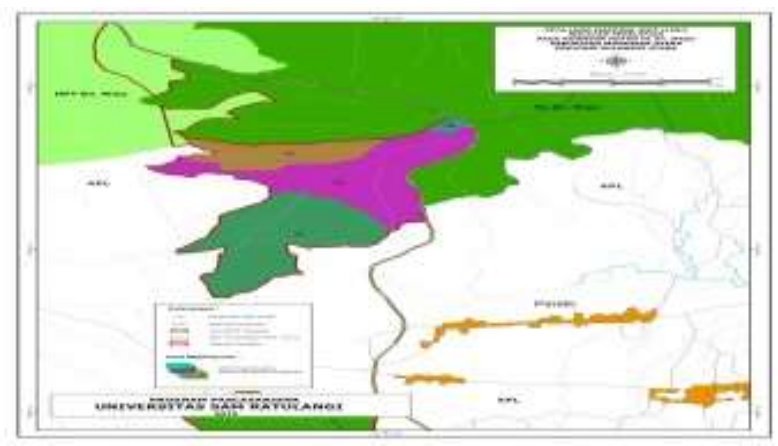

Gambar 7. Peta Land Mapbing pada kawasan HL Gn. Wiau 


\section{Prediksi erosi tanah}

Analisis pendugaan besar erosi dengan persamaan USLE dilakukan dengan pendekatan satuan unit lahan. Nilai parameter R, K, LS dan CP didapatkan dari data hasil pengolahan data besaran erosi pada lokasi penelitian sebagaimana tertera pada table 9 .

Tabel 9. Pendugaan Besaran Erosi

\begin{tabular}{rrrrrrrrr}
\hline No & No_LMU & Luas & R & K & LS & C & P & \multicolumn{1}{c}{ A } \\
\hline 1 & LMU1 & 15,52 & $2.761,50$ & 0,18 & 7,17 & 0,300 & 0,350 & 363,57 \\
2 & LMU2 & 21,78 & $2.761,50$ & 0,18 & 0,02 & 0,525 & 0,350 & 1,78 \\
3 & LMU3 & 13,08 & $2.761,50$ & 0,18 & 1,79 & 0,500 & 0,400 & 173,01 \\
4 & LMU4 & 6,45 & $2.761,50$ & 0,18 & 0,02 & 0,500 & 0,400 & 1,93 \\
5 & LMU5 & 8,87 & $2.761,50$ & 0,18 & 2,48 & 0,500 & 0,400 & 239,21 \\
6 & LMU6 & 2,52 & $2.761,50$ & 0,18 & 3,10 & 0,500 & 0,400 & 299,62 \\
7 & LMU7 & 39,50 & $2.761,50$ & 0,18 & 3,10 & 0,525 & 0,350 & 275,28 \\
8 & LMU8 & 3,98 & $2.761,50$ & 0,13 & 1,56 & 0,525 & 0,350 & 102,91 \\
9 & LMU9 & 5,52 & $2.761,50$ & 0,13 & 0,02 & 0,525 & 0,350 & 1,32 \\
10 & LMU10 & 5,69 & $2.761,50$ & 0,18 & 0,02 & 0,525 & 0,350 & 1,78 \\
11 & LMU11 & 7,93 & $2.761,50$ & 0,30 & 0,02 & 0,525 & 0,350 & 3,04 \\
12 & LMU12 & 1,95 & $2.761,50$ & 0,30 & 1,56 & 0,525 & 0,350 & 237,48 \\
13 & LMU13 & 18,66 & $2.761,50$ & 0,18 & 2,68 & 0,500 & 0,400 & 259,03 \\
14 & LMU14 & 23,17 & $2.761,50$ & 0,18 & 4,66 & 0,005 & 1,000 & 11,26 \\
15 & LMU15 & 10,47 & $2.761,50$ & 0,18 & 4,68 & 0,005 & 1,000 & 13,40 \\
16 & LMU16 & 60,27 & $2.761,50$ & 0,18 & 2,68 & 0,500 & 0,400 & 259,03 \\
17 & LMU17 & 2,37 & $2.761,50$ & 0,18 & 6,64 & 0,005 & 1,000 & 16,04 \\
18 & LMU18 & 62,98 & $2.761,50$ & 0,18 & 3,13 & 0,525 & 0,350 & 277,94 \\
19 & LMU19 & 23,65 & $2.761,50$ & 0,13 & 0,02 & 0,525 & 0,350 & 1,32 \\
20 & LMU20 & 25,94 & $2.761,50$ & 0,13 & 2,47 & 0,500 & 0,400 & 177,58 \\
21 & LMU21 & 72,13 & $2.761,50$ & 0,13 & 4,56 & 0,500 & 0,400 & 327,40 \\
22 & LMU22 & 3,24 & $2.761,50$ & 0,17 & 1,99 & 0,500 & 0,400 & 186,84 \\
23 & LMU23 & 167,29 & $2.761,50$ & 0,17 & 3,02 & 0,500 & 0,400 & 283,55 \\
24 & LMU24 & 151,66 & $2.761,50$ & 0,17 & 5,51 & 0,005 & 1,000 & 12,93 \\
25 & LMU25 & 40,21 & $2.761,50$ & 0,17 & 4,69 & 0,005 & 1,000 & 11,01 \\
26 & LMU26 & 3,65 & $2.761,50$ & 0,17 & 6,46 & 0,005 & 1,000 & 15,16 \\
\hline & & 798,47 & & & & & & \\
\hline & & & & & & & & \\
\hline
\end{tabular}

\section{Indeks Bahaya Erosi}

Perhitungan nilai erosi yang dapat ditoleransikan atau tolerable soil loss (TSL), mengunakan data jenis tanah dari Pusat Penelitian Tanah, Bogor (1995) yang menunjukkan bahwa di DTA danau Tondano dan sekitarnya memiliki kedalaman tanah efektif rata-rata adalah 1200 $1500 \mathrm{~mm}$, sub order tanah adalah enseptisol dengan nilai 1,00 umur guna tanah 400 tahun dan berat volume tanah (bulk density) 1,1 - 1,34 (g/cm3) dalam Walangitan, 2013, diperoleh nilai erosi yang dapat ditoleransikan berkisar antara $33-50.25$ Ton ha-1 tahun ${ }^{-1}$ sehingga nilai rata-rata 40.125 ton ha ${ }^{-1}$ $\operatorname{tahun}^{-1}$. Klasifikasi bahaya erosi dapat dilihat pada Tabel 10.
Tabel 10. Indeks Bahaya Erosi

\begin{tabular}{ccc}
\hline $\begin{array}{c}\text { Kelas } \\
\text { Bahaya Erosi }\end{array}$ & $\begin{array}{c}\text { Laju Erosi } \\
\text { (Ton/ Ha/ Tahun) }\end{array}$ & Keterangan \\
\hline I & $\mathrm{I}<15$ & Sangat Ringan \\
II & $15-60$ & Ringan \\
III & $60-180$ & Sedang \\
IV & $180-480$ & Berat \\
V & $>480$ & Sangat Berat \\
\hline
\end{tabular}

Sumber : Dirjen RRL, 1998

Hasil perhitungan dugaan erosi diwilayah penelitian, didominasi oleh lokasi dengan klasifikasi sangat ringan sebesar 451, $50 \mathrm{Ha}$ atau $56,55 \%$, kategori ringan sebesar 20,61 ha $(2,58 \%)$ kategori sedang sebesar 195,51 Ha $(24,49 \%)$ dan kategori berat 130,85 hektar $(16,39 \%)$, besaran dugaan klasifikasi kelas bahaya erosi sebagaimana tersaji gambar 8 .

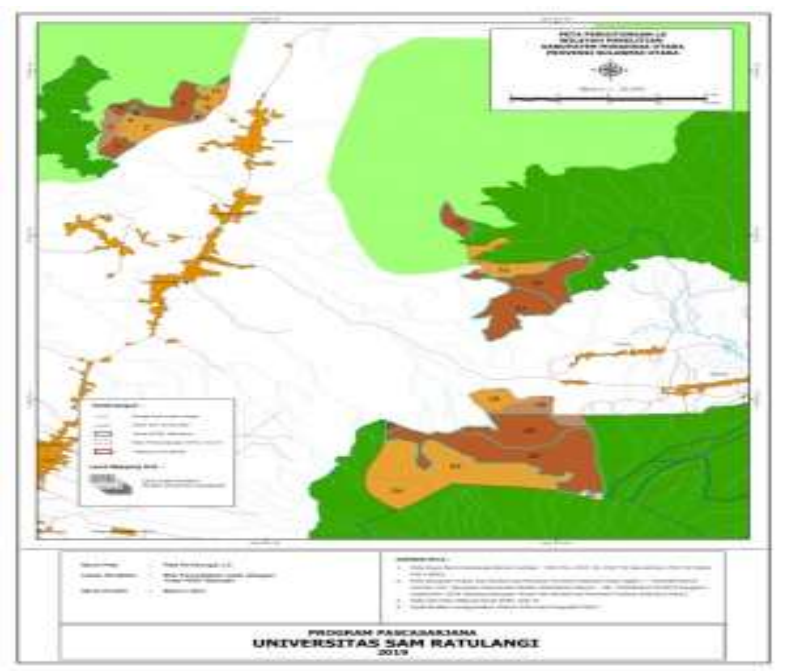

Gambar 8. Sebaran Kerentanan Erosi pada lokasi penelitian

\section{Model Pengelolaan}

Pembuatan Land Mapping Unit (LMU) menggunakan Sistem Informasi Geografis dengan menggunakan teknik overlay (tumpangsusun data), dimana beberapa data disusun, dijadikan satu kemudian dianalisis sesuai dengan kebutuhan. Berdasarkan hasil tumpangsusun data dimaksud, terdapat 26 Land Mapping Unit (LMU) dengan luas keseluruhan 798,47 hektar yang tesebar pada empat kawasan hutan yaitu : Hutan Lindung (HL) Gn. Klabat, sebanyak 8 polygon seluas 487.76 hektar, kawasan HL Gn. Wiau, sebanyak 4 polygon seluas 148,79 hektar, Hutan Produksi Terbatas (HPT) Gn. Saoan sebanyak 12 polygon seluas 132,80 hektar dan HPT Gn. Wiau sebanyak 2 polygon dengan luas 29,12 hektar. 
Mengingat wilayah penelitian memiliki fungsi Hutan Lindung (HL) dan hutan Produksi Terbatas (HPT) maka Model pengelolaan pada wilayah penelitian yang terletak pada kawasan HL adalah model pengelolaan Hutan Kemasyakatan (HKm), sedangkan untuk wilayah penelitian yang terletak pada HPT model pengelolaan yang dipilih adalah Hutan Tanaman Rakyat (HTR).

Adapun dengan luas areal pada model pengelolaan $\mathrm{HKm}$ sebanyak 12 polygon dengan luas 636,55 hektar dan HTR sebanyak 14 polygon dengan luas 161,92 hektar.

\section{Arahan Prioritas Pengelolaan}

Prioritas pengelolaan yang akan dilakukan pada wilayah penelitian ini adalah dengan mengkombinasikan sasaran ekonomi, ekologi dan sosial, hasil analisa dengan AHP untuk menentukan Prioritas Pola pengelolaan dilakukan dengan Land Utilities Type (LUT) Agroforestry, LUT pengkayaan dan LUT Reboisasi. Wawancara yang dilakukan didesa yang berada diwilayah penelitan, Agroforestry yang dilakukan masyarakat setempat yaitu dengan penanaman kayu yang dikombinasikan dengan tanaman aren dan penanaman pohon yang ditumpangsarikan dengan tanaman talas.

Analisa AHP dengan sasaran ekonomi, ekologi dan sosial menghasilkan bobot nilai sebagai berikut :

\section{Sasaran Ekonomi}

Arahan Prioritas Pengelolaan Pola Agroforestry dengan bobot nilai tertinggi 652 poin, dilevel kedua kegiatan Prioritasnya adalah Pengkayaan dengan nilai bobot 217 poin dan terakhir kegiatan Prioritas Pola Reboisasi dengan nilai bobot 130 poin.

\section{Sasaran Ekologi}

Arahan Prioritas Pengelolaan Pola Agroforestry dengan nilai bobot 111, selanjutnya kegiatan Prioritasnya adalah Pola Pengkayaan dengan nilai bobot 333 poin dan yang terakhir adalah Pola Reboisasi dengan nilai bobot 556 .

3. Sasaran Sosial

Alternatif Prioritas Pengelolaan Pola Agroforestry dengan nilai bobot 652, di level kedua kegiatan Prioritasnya adalah Pola Pengkayaan dengan nilai bobot 217 dan yang terakhir adalah Pola Reboisasi dengan nilai bobot 130 .

\section{Kebijakan Pemerintah untuk Penyelesaian Penguasaan Lahan Dalam Kawasan Hutan}

Polarisasi Kebijakan Pemerintah untuk penyelesaian Penguasaan Lahan dalam Kawasan Hutan dapat dilakukan beberapa tindakan diantaranya :

a. Review Tata Ruang/ Usulan perubahan Fungsi Kawasan Hutan secara berkala

Perubahan fungsi Kawasan Hutan berkaitan pula dengan perubahan Pola Ruang baik ditingkat Kabupaten/ Kota maupun perubahan Pola Ruang di Tingkat Provinsi sebagaimana Undang-Undang Nomor : 26 Tahun 2007 tentang Penataan Ruang khususnya diatur pasal 20, 23 dan pasal 26, mengisyaratkan bahwa untuk dilakukannya peninjauan kembali (review) Rencana Tata Ruang Wilayah baik ditingkat Kabupaten dan Kota maupun di Tingkat Provinsi dapat dilakukan setiap 5 tahun sekali.

Sesuai dengan Peraturan Menteri Kehutanan Nomor : P. 34/Menhut-II/2010 tentang Tata Cara Perubahan Fungsi Kawasan Hutan, sebagaiman telah beberapa kali dirubah terakhir dengan Peraturan Menteri Lingkungan Hidup dan Kehutanan Nomor : P.16/MenLHK-II/2015 tentang Perubahan Kedua Atas Peraturan Menteri Kehutanan Nomor P.34/Menhut-II/2010 tentang Tata Cara Perubahan Fungsi Kawasan Hutan, tertulis bahwa tujuan dilakukan usulan Perubahan fungsi kawasan hutan untuk memantapkan dan mengoptimalisasikan fungsi kawasan hutan. Usulan perubahan Fungsi kawasan Hutan untuk tingkat Kabupaten dapat diajukan melalui Bupati dengan pengajuan surat yang ditujukan kepada Menteri yang membidangi Kehutanan. Apabila lokasi usulan Perubahan fungsi kawasan hutan melintasi lebih dari satu Kabupaten, maka usulan perubahan Fungsi dilakukan melalui Gubernur.

b. Perubahan fungsi kawasan hutan secara Parsial

Wilayah penelitian dapat juga diajukan untuk dilakukan perubahan fungsi secara parsial mengingat sebagian kawasan hutan baik pada kawasan HL Gn. Wiau, HPT Gn.Saoan maupun kawasan HPT Gn.Wiau sebagiaan besar telah berubah menjadi lahan pertanian masyarakat. Letak kawasan hutan yang terlalu dekat dengan pemukiman masyarakat yang menyebabkan hutan menjadi open access.

Perubahan fungsi secara parsial umumnya dilakukan untuk menurunkan grade fungsi kawasan hutan, misalnya menurunkan status HL menjadi Hutan Produksi Terbatas (HPT), HPT 
menjadi Hutan Produksi, atau HPT menjadi Hutan Produksi yang dapat di-Konversi (HPK).kawasan hutan yang berstatus HPK lebih mudah bagi Pemerintah Kabupaten/ Kota untuk pengajuan pelepasan kawasan hutan menjadi bukan kawasan hutan atau Areal Pengunaan Lain (APL).

c. Pola Percepatan Penyelesaian Penguasaan Tanah dalam Kawasan Hutan (PPTKH).

Penyelesaian Penguasaan Tanah dalam Kawasan Hutan (PPTKH) merupakan turunan dari Peraturan Presiden Republik Indonesia Nomor : 88 Tahun 2017. Prinsip dasar dari terbitnya Perpress No. 88 Tahun 2017 adalah memberikan akses dan asset kepada masyarakat. Pemberian asses kepada masyarakat dalam bentuk pengelolaan Hutan berupa Perhutanan Sosial, dengan model Pengelolaan Kemasyarakatan (HKm), Hutan Tanaman Rakyat (HTR), maupun Hutan Desa (HD) atau pun Kemitraan Kehutanan. Kesemua program tersebut merupakan bagian dari program Perhutanan Sosial. Adapaun maksud pemberian asset dimana lokus areal dimaksud diusulkan untuk perubahan batas, yang kelak menjadi bukan kawasan hutan atau berubah menjadi Areal Penggunaan Lain (APL), sehingga output akhir pada lokus lokasi yang diusulkan adalah terbitnya sertifikat kepemilikan.

Sesuai dengan Peraturan Menteri (PerMen) Koordinator Bidang Perekonomian Nomor : 3 Tahun 2018 tentang Pedoman Pelaksanaan Tugas Tim Inventarisasi dan verifikasi penguasaan tanah dalam kawasan hutan, apabila rekomendasi yang diberkan berupa perubahan batas, mekanisme yang dilakukan mengacu pada PerMen Kehutanan Nomor: P.44/ Menhut-II/2012 jo. Peraturan Menteri Kehutanan P.62/Menhut-II/2013 tentang pengukuhan kawasan hutan namun pelaksanaannya tanpa melalui tahapan pemancangan batas sementara dan inventarisasi hak-hak pihak ketiga, sehingga pelaksanaannya langsung pada kegiatan tata batas, denga demikian kegiatan ini lebih sederhana dibandingkan dengan prosedur pengukuhan pada umumnya.
Ketiga Pola penyelesaian Penguasaan tanah dalam kawasan hutan baik review tata ruang, perubahan fungsi secara parsial maupun mengikuti pola PPTKH Per Pres 88 tahun 2017 kesemuanya dibutuhkan peranan dan keseriusan Pemerintah Daerah untuk memberikan usulan, gambaran lokasi dan tentu berperan aktif baik di Tingkat Provinsi maupun di Tingkat Pusat agar usulannya dapat dipahami pusat sebagai sebuah usulan yang penting untuk ditindaklanjuti.

Kawasan hutan yang berada di dalam wilayah penelitian ini terdiri atas 4 (empat) kawasan hutan yaitu ; Hutan Lindung (HL) Gunung Klabat, HL Gn. Wiau, Hutan Produksi Terbatas (HPT) Gn. Saoan dan HPT Gn. Wiau. Hasil penelurusan dokumen hasil tata batas pada Balai Pemantapan Kawasan hutan Wilayah VI Manado, ke-empat kawasan yang berada diwilayah penelitian telah ditetapkan dengan SK Menteri Kehutanan sebagaimana tertera pada Tabel 11.

\begin{tabular}{|c|c|c|c|c|}
\hline No. & $\begin{array}{c}\text { Nama } \\
\text { Kawasan }\end{array}$ & $\begin{array}{c}\text { SK } \\
\text { Penetapan }\end{array}$ & Tanggal & Luas (Ha) \\
\hline 1. & $\begin{array}{l}\text { HL Gn. } \\
\text { Klabat }\end{array}$ & $\begin{array}{l}\text { SK.1827/Menhu } \\
\text { t-II/KUH/2014 }\end{array}$ & $\begin{array}{l}25 \text { Maret } \\
2014\end{array}$ & $5.617,88$ \\
\hline 2. & HL Gn. Wiau & $\begin{array}{l}\text { SK.1837/Menh } \\
\text { ut II/KUH/2014 }\end{array}$ & $\begin{array}{l}25 \text { Maret } \\
2014\end{array}$ & $6.294,45$ \\
\hline 3. & $\begin{array}{l}\text { HPT Gn. } \\
\text { Saoan }\end{array}$ & $\begin{array}{l}\text { SK.1841/Menh } \\
\text { ut- } \\
\text { VII/KUH/2014 }\end{array}$ & $\begin{array}{l}25 \text { Maret } \\
2014\end{array}$ & $4.157,94$ \\
\hline 4. & $\begin{array}{l}\text { HPT Gn. } \\
\text { Wiau }\end{array}$ & $\begin{array}{l}\text { SK.1833/Menh } \\
\text { ut } \\
\text { VII/KUH/2014 }\end{array}$ & $\begin{array}{l}25 \text { Maret } \\
2014\end{array}$ & $3.764,02$ \\
\hline
\end{tabular}

Sumber : Statistik BPKH Wilayah VI Tahun 2018.

Sesuai dengan arahan kebijakan pada Peraturan Presiden Nomor : 88 Tahun 2017, kebijakan dengan mengeluarkan bidang tanah dari dalam kawasan hutan melalui perubahan batas kawasan hutan atau melakukan perubahan kawasan hutan menjadi areal Penggunaan Lain (APL), merupakan kawasan hutan yang masih dalam tahap penunjukan kawasan hutan. Adapunpun kawasan hutan yang berada dalam wilayah penelitian merupakan kawasan hutan yang telah ditetapkan, sehingga kebijakan Pemerintah yang dapat dilakukan untuk penyelesaian penguasaan tanah dalam kawasan hutan ini adalah dengan memberikan akses pengelolaan kawasan berupa Program Perhutanan Sosial dengan Model Pengelolaan Hutan Kemasyarakatan (HKm) dan Hutan Tanaman Rakyat (HTR), dengan masingmasing jangka waktu pengelolaan selama 35 tahun dan dapat diperpanjang sesudahnya. 


\section{KESIMPULAN DAN SARAN}

\section{Kesimpulan}

- Model Pengelolaan yang terbentuk pada wilayah penelitian berupa Model Pengelolaan Hutan Kemasyarakatan (HKm) dan Hutan Tanaman Rakyat (HTR) dan dengan jangka waktu pengelolaan selama 35 tahun dan dapat diperpanjang sesudahnya.

- Arahan Prioritas pengelolaan sesuai analisa AHP dengan sasaran ekonomi, ekologi dan sosial adalah dengan melaksanakan model pengelolaan dengan Land Utilities Type (LUT) Agrorestry, LUT pengkayaan dan LUT reboisasi dengan bobot nilai sasaran ekonomi sebesar 429 poin, nilai sasaran ekologi 143 poin dan bobot nilai sasaran sosial sebesar 429 poin. Adapun Arahan kebijakan Pemerintah untuk penyelesaian penguasaan tanah dalam kawasan hutan ini adalah dengan memberikan akses pengelolaan terhadap kawasan hutan berupa Program Perhutanan Sosial dengan Model Pengelolaan Hutan Kemasyarakatan (HKm) dan Hutan Tanaman Rakyat (HTR).

\section{Saran}

- Menggiatkan rencana aksi agar pelaksanaan model pengelolaan prioritas berupa kegiatan Agroforestri, pengkayaan dan reboisasi agar segera dilakukan dilapangan. Hal ini diharapkan dapat segera memperbaiki tutupan lahan sehingga laju erosi permukaan yang terjadi pada unit-unit lahan diwilayah penelitian dapat diperlambat.

- Melakukan sosialiasi dan peningkatan kesadaran masyarakat secara berkala khususnya kepada masyarakat yang berada disekitar wilayah penelitian.

\section{DAFTAR PUSTAKA}

Anonim 2014. Rencana Teknik Rehabilitasi Hutan dan Lahan Daerah Aliran Sungai (RTK-RHL Das) Tahun 2014-2029, BPDAS Mahakam Berau.

Anonim 2018. Laporan Statistik Balai Pemantapan Kawasan Hutan Wilayah VI Tahun 2018.

Anonim, 2019. Laporan Penutupan lahan hasil Hasil Penafsiran citra resolusi sedang tahun 2018, BPKH Wialyah VI Manado.

Anonim. 1998. Petunjuk Pelaksanaan Penyusunan RTL-RLKT. Direktorat
Jenderal RRL, Departemen Kehutanan RI.Jakarta

Arsyad Sitanala, 2010. Konservasi Tanah dan Air. Edisi Kedua, IPB Press. Bogor.

As-Syakur Abd. Rahman 2008. Prediksi Erosi Dengan Menggunakan Metode Usle Dan Sistem Informasi Geografis (SIG) Berbasis Piksel di Daerah Tangkapan Air Danau Buyan Pusat Penelitian Lingkungan Hidup (PPLH) Universitas Udayana.

Badan Pusat Statistik Kabupaten Miinahasa Utara, 2018. Kecamatan Dimembe Dalam Angka 2018

Gamin. 2014. Resolusi Konflik Dalam Pengelolaan Hutan Untuk Mendukung Implementasi Redd+, Disertasi.

Jayanath Ananda, Gamini Herath, 2003, The use of Analytic Hierarchy Process to incorporate stakeholder preferences into regional forest planning, Forest Policy and Economics, (5) 13-26;

JICA. 2001. The Study On Critical Land and Protection Forest Rehabilitation at Tondano Watershed in The Republic of Indonesia. Draft Final, Volume I, Main Report. Nippon Koei Co.,Ltd. and Kokusai Kogyo Co.,Ltd.

Kartodihardjo H, Nugroho B, Putro HR. 2011. Pembangunan Kesatuan Pengelolaan Hutan (KPH) Konsep, Peraturan Perundangan dan Implementasi. Direktorat Wilayah Pengelolaan dan Penyiapan Areal Pemanfaatan Kawasan Hutan, Ditjen Planologi, Kementerian Kehutanan.

Kartodihardjo H. 1998. Peningkatan Kinerja Pengusahaan Hutan Alam Produksi Melalui Kebijaksanaan Penataan Institusi [disertasi]. Bogor (ID): Program Pasca Sarjana Institut Pertanian Bogor.

Kartodihardjo, H. 2011. Penanganan Konflik Kehutanan: Peran dan Pengalaman Dewan Kehutanan Nasional. Forum DKN Untuk Mediasi Konflik.Konggres Kehutanan Indonesia (KKI) ke-V, Kementerian Kehutanan Jakarta.

Lillesand, T. M., Kiefer, R. W. \& Chipman, H. W., 1990. Remote Sensing and Image Interpretation. Sixth ed. New York: Jhon Willey \& Son. 
Saaty, T. L. 1993. The Analytical Hierarchy Process: Planning, Priority, Setting, Resource Allocation. Pittsburgh: University of Pittsburgh Pers.

Turner MG, Pearson SM, Bolstad P and Wear DN.2003. Effects of land-cover change on spatial pattern of forest communities in the Southern Appalachian Mountains (USA). J.Landscape Ecology 18(5): 449-464.

Vörösmarty C.J, Green P, Salisbury J, Lammers R. 2000. Global water resources: Vulnerability from climate change and population growth. J. Science. 289: 284288.

Walangitan, H. 2008. Analisis Keragaan Sistem Usahatani Konservasi Pada Daerah Tangkapan Air (Catchment Area) Danau Tondano Kabupaten Minahasa Sulawesi Utara. Disertasi.
Walangitan, H. 2012. Analisis Keragaan Sistem Usahatani Konservasi Pada Daerah Tangkapan Air (Catchment Area) Danau Tondano Kabupaten Minahasa Sulawesi Utara. Disertasi.

Walangitan, H. 2013. Laporan Rencana Induk Pembangunan Areal Model Das Mikro (MDM) Sub-Sub Das Talawaan SWP DAS Likupang Kabupaten Minahasa Utara, Balai Pengelolaan Daerah Aliran Sungai Tondano

Wang, G.X.Wang, Y.B, Qian, J and Wu, Q.B. 2006. Land cover change and its impacts on soil $C$ and $N$ in two watersheds in the center of the Qinghai-Tibetan Plateau. J. Mountain Research and Development 26 (2): 153-162.

Wischmeier, W. H. and D. D. Smith. 1978. Predicting Rainfall Erosion Losses. A guide to Conservation Planning. USDA Hand Book. No. 537. 